\title{
The Extent of Practicing Management by Love in the Inclusive Schools in Qatar in Accordance with Several Variables from the Perspective of Administrators
}

\author{
Abdulnaser A. Fakhrou ${ }^{1}$, Ibrahim Ali al-Baher ${ }^{1} \&$ Sara A. Ghareeb $^{2}$ \\ ${ }^{1}$ Department of Psychological sciences, College of Education, Qatar University, Qatar \\ ${ }^{2}$ Department of Mathematics, Ministry of Education, Kuwait \\ Correspondence: Abdulnaser A. Fakhrou, Department of Psychological Sciences, College of Education, Qatar \\ University, Qatar.
}

Received: June 2, 2020

Accepted: July 15, 2020

Online Published: September 25, 2020

doi:10.5539/ies.v13n10p124

URL: https://doi.org/10.5539/ies.v13n10p124

\begin{abstract}
The present study aimed to explore the extent of practicing management by love in the inclusive schools in Qatar from the perspective of administrators at these schools. The sample consists from 342 administrators who were selected through using the random clustering sampling method. A descriptive approach was adopted. A questionnaire was used to meet the study's goals. It was found that the extent of practicing management by love in the inclusive schools in Qatar is moderate. It was found that there is a statistically significant difference-at the statistical significance level of $(\mathrm{a} \leq 0.05)$-between the respondents' attitudes which can be attributed to gender. The latter differences are for the favor of males. It was found that there isn't any statistically significant difference -at the statistical significance level of $(\mathrm{a} \leq 0.05)$-between the respondents' attitudes which can be attributed to experience, or academic qualification. The researchers recommend conducting more studies that aim at shedding a light on management by love and its impact on the performance of educational institutions.
\end{abstract}

Keywords: management by love, inclusive schools, inclusive education, Qatar

\section{Introduction}

Education plays a significant role in developing societies and achieving advancement. It enables young people to turn their dreams into reality. In this regard, inclusive schools aim at delivering education that develops society. They aim at raising up individuals who are capable of serving their country. Inclusive schools aim at raising up good adolescents and improving their potentials and capabilities. They aim at enabling adolescents to do their duties. These goals can't be met without having a wise administration in inclusive schools. The administrations of educational institutions must be unbiased. They must accept diversity and have clear objectives. They must understand the complex reality. They must implement effective mechanisms that enable them to understand reality.

Practicing management by love enables educational institutions to overcome the organizational problems and conflicts. It promotes stability in educational institutions. It fosters development and growth. It promotes love, respect and appreciation among employees in the educational institutions. It encourages the staff to exert more effort to have a better future. It promotes collaboration, and optimism. It creates a healthy organizational climate in educational institutions. That shall promote love for work among employees. It shall make employees keen on achieving the goals of their educational institution. It shall make the employees keen on developing their educational institution. Practicing management by love shall make the employees keen on meeting the goals of their institution rather than meeting their own needs and desires.

Through management by love, there shall be changes made in a regular manner in the educational institutions. Such changes are based on innovation and aim at fostering development. They aim at utilizing the available organizational resources and potentials in order to develop employees and their talents. It should be noted that management by love is based on showing appreciation to the employees who make achievements, including little achievements.

Through practicing management by love, the relationships between employees shall be based on love, empathy and altruism. Practicing management by love shall make the employees keen on developing the organization. That 
shall lead to having a healthy organizational climate. Such a climate is free from depression, despair, and rejection for handling responsibility. Through practicing management by love, organizational justice shall be dominant in the whole educational institution.

Through practicing management by love, the employees shall seek exchanging expertise with each other. They shall have strong social bonds. Through practicing management by love, all employees shall benefit from meeting the pre-set interests and goals. Practicing management by love shall promote trust, integrity, justice and altruism in the organization.

Hence, management by love aims at promoting positive values. It aims at addressing the obstacles and challenges that might by faced by educational institutions. It aims at creating a positive organizational climate. It aims at promoting psychological stability among the employees. It promotes stability in educational institutions. It enables educational institutions to meet their vision, mission and goals efficiently and effectively. It makes employees realize how important their role and achievements at the educational institutions are. Realizing such importance shall increase the employees' capability to meet the goals of the educational institutions effectively. It shall promote trust between the employees and the administration of their educational institutions. Promoting such trust shall positively affect the organizational climate. It shall promote love, and dedication. It shall promote positive interaction between the administration and the employees (Sandford, 2000).

Practicing management by love shall positively affect one's behavior at work. One's behavior at work is affected by several factors. Such factors may include: years of experience, gender and academic qualification. Each gender is associated with certain physiological, psychological and sociological attributes (Al-Bahar, 2018).

Management by love is a modern concept that integrates management and psychology. It can be noticed that the failure of several management theories in interpreting the reasons behind having effective management isn't attributed to the failure of their approaches. In fact, such failure is attributed to the absence of love.

Love is a key factor which affects the degree to which organizations achieves success. Therefore, practicing management by love shall lead to achieving a kind of balance between logic and emotion in organizations. It shall enable administrations to make wise decisions.

The organizations that practice management by love seek providing their employees with knowledge in an ongoing manner. They also seek teaching and developing their employees in an ongoing manner. They are very willing to acknowledge their mistakes and weaknesses. Such willingness shall enable those organizations to develop themselves, delegate powers, and form work teams effectively. The organizations that practice management by love offer unconditional love for their employees. Therefore, practicing management by love gives organizations much strength (Al-Taweel, 2010).

Practicing management by love requires meeting several requirements by the organization. For instance, the organization must be capable of adapting itself with the latest changes. It must be enjoying much stability. It must increase the employees' engagement in the planning, implementation, monitoring and decision making processes (Al-Zou'bi, 2001).

It is very important to employ methods that promote love in the organization. Therefore, Harris (1996) wrote a book titled Getting Employees to Fall in Love with Your Company. This book includes several methods that promote love among employees for their organization. Such methods include: unleashing the employees' potentials, ensuring that the employees are enjoying a stable family life, and having open communication at the workplace. They include listening well to employees. They include engaging employees in the decision making process. They include eliminating the social barriers when communicating with the employees. They include promoting a life-long learning approach among employees and raising the employees' job security level (cited in Abu Al-Naser, 2005).

Lee (1973) written a book titled The Colors of Love. Through this book, Lee (1973) offers a simile. For instance, he suggests that love is similar to a wheel consisting from several colors. Each color represents a specific kind of love. The latter wheel consists from the following colors: (red, green and blue). The latter types of love are:

Eros: It is a Greek word which means romantic or sexual love. Lee (1973) suggests that this type of love involves physical and emotional love.

Ludus: It is a Greek word which means (a game). It refers to the love that is experienced by the partners who want to have fun and indulge themselves without having a serious relationship. Those partners don't want to have a serious commitment. They don't want to experience deep intimacy.

Storage: It is a Greek word which means family love (Lee, 1973). 
The latter type of love is represented in the love that family members have for each other. One has such love for his/her father, mother, children, sisters, brothers and relatives. According to Lee (1973), since one can mix colors to come up with new colors, one can also combine several types of love to experience a new type of love (Lee, 1973). The color wheel theory of love which was developed by Lee (1973) enriched the theoretical framework of the present study. Based on the latter theory, the researchers of the present study concluded that having good work relationships between colleagues at the workplace requires having love. They concluded that the love-based relationship at the workplace is a strong relationship. They concluded that the latter relationship provides employees with guidance and appreciation.

Sternberg (2007) developed a tri-dimensional theory of love. This theory suggests that love consists from the three elements. These elements are:
1) Intimacy
2) Passion
3) Commitment

Sternberg (2007) uses the term (consummate love) for referring to the love that is based on intimacy, passion and commitment. The consummate love is the strongest and most sustainable love. It is very rare. In case there is passion in the relationships existing at schools workplaces, there shall be commitment in such relationships. That applies whether such relationships are vertical or horizontal relationships. Vertical relationships refer to the relationships between the boss and his/her subordinate. Horizontal relationships refer to the relationships between colleagues of the same administrative level (Sternberg, 2007).

Sanford (1998) suggests that there are loving administrators and administrators who aren't so. The administrators who aren't loving don't love nor respect themselves. They don't accept criticism. They aren't willing to listen to the things they don't like. They don't like helping others to achieve success. They don't allow others to excel. They don't acknowledge their mistakes. They don't apologize for the mistakes they have committed. They don't change their views even if there are proofs indicating that their views are wrong. They are concerned only in hearing good news. They hesitate when making decisions. That's because they don't enjoy a high self-confidence level. Thus, the administrators who aren't loving exaggerate in the extent of exercising their powers at the workplace. They deal with employees in a tough manner. They concentrate on trivial things. They aren't self-disciplined (Sanford, 1998).

\subsection{Statement of the Problem and the Study's Questions}

Each educational institution aims at showing the highest levels of performance effectiveness and efficiency. It seeks developing the employees professionally. It promotes interaction between employees at the workplace. It seeks engaging employees and integrating them into the workplace environment. It engages employees in doing duties.

The researchers of the present study noticed that there are differences between the employees in inclusive schools in Qatar in terms of the extent of love they have for their jobs. When one loves his/her job, he/she shall perform his/her work tasks in the best possible manner. Loving the job increases the extent of one's interaction with others. It increases the extent of one's integration into the workplace environment. Due to the significance of love at the workplace, employers must give attention to appreciation, rewarding, and motivation. Giving such attention shall promote love among employees in institutions. That is confirmed by Mohammad (2020), Khandelwal (2018), and Satu (2013). The present study aimed to explore the extent of practicing management by love in the inclusive schools in Qatar. To be more specific, the present study aimed to answer the following questions:

Question one: What is the extent of practicing management by love in the inclusive schools in Qatar in terms of coordination, guidance, and appreciation from the perspective of administrators?

Question two: Is there any statistically significant difference-at the statistical significance level of (a $\leq 0.05$ )-between the respondents' attitudes which can be attributed to (gender, experience or academic qualification)?

\subsection{The Study's Significance}

The significance of the present study is illustrated below:

Theoretical significance: The present study enriches the relevant literature. It enriches the literature that sheds a light on management by love in Qatar.

Practical significance: The present study enables decision makers and policy makers to improve the social 
environment of inclusive schools in Qatar. It enables the latter decision makers and policy makers to promote harmony between employees and the administration at the inclusive schools located in Qatar. It enables the administration of inclusive schools in Qatar to meet the intended goals effectively and efficiently.

\subsection{Definition of Terms}

The study's terms are defined below:

Management by love: It refers to the management that emphasizes the significance of social relationships. It is based on cultural values. It aims at retaining the social capital. In the present study, the dimensions of management by love are: (coordination, guidance, and appreciation) (Al-Soud, 2012).

Inclusive schools: They refer to the schools that integrate the students with special needs in the classrooms of normal students. These schools aim at providing the students with special needs with special services and support (Al-Wabili, 2018).

\subsection{The Study's Limits}

The study's limits are listed below:

Human limits: The present study targets the administrators who work at inclusive schools in Qatar.

Temporal limits: The present study was conducted during the second semester of the academic year (2019/2020).

Spatial limits: The present study was conducted in inclusive schools in Qatar.

\subsection{Previous Studies}

The researchers listed below the studies that were reviewed by them. Those studies are arranged from the oldest to the newest. Some of those studies are published in Arabic language and some of them are published in English language.

Viviano (2012) aimed to explore the degree to which teachers love and trust the administrators. Having much love and trust for the administrators shall enable teachers to develop and upgrade the educational institution. It shall encourage teachers to gain knowledge about the contemporary trends. It shall increase the teachers' retention level (Viviano, 2012)

Satu (2013) aimed to shed a light on love-based leadership. He aimed to explore the role of love-based leadership in early childhood education. Love-based leadership aims at developing the professional skills of teachers. In Finland, the educational system provides conditions that enable leaders to practice love-based leadership. The latter researcher suggests addressing issues related to motherhood-based leadership through the curricula used for developing the teachers of early childhood educational programs (Satu, 2013).

Maataa (2014) aimed to explore the meaning of love-based leadership and its impact on teachers' performance. The latter leadership involves a mixture of love and power. It aims at offering educational activities that promote commitment among students. The sample consists from 356 teachers in Finland. The latter researcher recommends exerting more effort to provide students with more expertise that enable them to succeed. Such expertise can be provided through practicing love-based leadership in schools (Maataa, 2014)

Al-Soud (2015) aimed to explore the most important contemporary trends in the educational administration field. He aimed to shed a light on the management by love theory. The latter theory suggests that administrators must give more attention to social and humanitarian issues. The latter scholar suggests that management by love is similar to maternity. That is because both of them are free from pain and distress. It's because both of them aim at delivering a noble message and offering great outcomes. It's because both of them are associated with sacrifice and altruism (Al-Soud, 2015).

Based on the management by love theory, the failure of many management theories isn't attributed to shortcomings in them. In fact, such failure is attributed to the absence of love and passion. The management by love theory suggests that management should be based mainly on love. Based on the latter theory, love serves as the magical stick and a key instrument. Based on the latter theory, love significantly affects the success level achieved by organizations. The latter theory suggests that there are 5 types for love. These types are: (1)- love for the institution, 2)-love for the employees, 3)-love for the customers, 4)-love for the surrounding society, and 5)- the love that the leader has for himself/herself. Based on the management by love theory, the leader must have the leadership skills that enable him/her to practice management by love effectively (Al-Soud, 2015)

Al-Hajar (2017) aimed to explore the meaning and characteristics of the authentic leadership. He aimed to explore the extent of practicing authentic leadership by the secondary school principals in Gaza. The sample consists from 
90 female and male principals and 474 female and male teachers. It was found that the extent of practicing authentic leadership by the secondary school principals in Gaza is moderate (Al-Hajar, 2017).

Ricky (2017) aimed to explore the perceptions of academic leaders for love-based leadership in Indonesian higher education institutions. The sample consists from 30 academic leaders. Those leaders were selected from Indonesian higher education institutions. It was found that the love-based academic leadership emphasizes the significance of spiritual and relational aspects. It was found that academic leaders in Indonesia seek promoting cooperation and settling conflicts. It was found that the latter leaders are keen on holding institutional meetings and one on one meetings (Ricky, 2017).

Mehta (2018) aimed to develop a scale for measuring the extent of practicing love-based leadership in the social institutions in South America. This scale sheds a light on psychological, emotional, spiritual, and philosophical areas. The sample consists from 130 managers. The study sheds a light on 13 principles. Such principles are related to the leaders' motives, attributes, attitudes and behaviors. They are related to love-based leadership. It was found that love-based leadership must be practiced with reason (Mehta, 2018)

Reviewing the aforementioned studies assisted the researchers of the present study in choosing the suitable approach, and statistical methods. It assisted the researchers in developing the theoretical framework and the instrument of the present study. It assisted the researchers in choosing the study's variables. To be specific, the instrument was developed based on several studies, including the ones conducted by Al-Soud (2015), Al-Hajar (2017) and Ricky (2017). Similar to the aforementioned studies, the present study sheds a light on management by love. Similar to the studies conducted by Mohammad (2020), and Satu (2013), the present study sheds a light on guidance and appreciation. Contrary to the aforementioned studies, the present study sheds a light on the administrators who work at the inclusive schools in Qatar. The present study sheds a light on variables that the aforementioned studies didn't shed a light on.

\section{Methodology}

\subsection{Approach}

The researchers adopted a descriptive approach. They used a survey to meet the study's goals.

\subsection{Population}

The population consists from all the administrators who work at the inclusive schools in Qatar (i.e. 2280 administrators). Table 1 presents the distribution of the study's population in accordance with gender, academic qualification and experience.

Table 1. The distribution of the study's population in accordance with gender, academic qualification and experience

\begin{tabular}{cccc}
\hline Variable & Category & Frequency & Total \\
\hline \multirow{2}{*}{ Gender } & Male & 1456 & \multirow{2}{*}{2280} \\
& Female & 854 & \\
\hline \multirow{3}{*}{ Academic qualification } & Postgraduate degree & 283 & \\
& BA degree & 914 & \multirow{2}{*}{2280} \\
& Diploma & 834 & \\
& Secondary school certificate & 249 & \\
\hline \multirow{2}{*}{ Experience } & Five years or less & 1353 & \multirow{2}{*}{2280} \\
& More than five years & 927 & \\
\hline
\end{tabular}

*Source: The Ministry of Higher Education and Scientific Research (2019).

Through using Stephen Thompson's equation, the researchers calculated the required sample size. The researchers used the random stratified sampling method. The statistical significance level is $(a \leq 0.05)$. Based on Stephen Thompson's equation, the sample must be consisting from 310 administrators at least. Therefore, the researchers distributed 350 questionnaire forms. 342 questionnaire forms were retrieved and analyzed. Table (2) presents the distribution of the sample in accordance with gender, academic qualification and experience. 
Table 2. The distribution of the sample in accordance with gender, academic qualification and experience

\begin{tabular}{cccc}
\hline Variable & Category & Frequency & Total \\
\hline \multirow{2}{*}{ Gender } & Male & 213 & \multirow{2}{*}{342} \\
& Female & 129 & \\
\hline \multirow{3}{*}{ Academic qualification } & Postgraduate degree & 64 & \\
& BA degree & 98 & \multirow{2}{*}{342} \\
& Diploma & 109 & \\
& Secondary school certificate & 71 & \\
\hline \multirow{2}{*}{ Experience } & Five years or less & 204 & \multirow{2}{*}{342} \\
& More than five years & 138 & \\
\hline
\end{tabular}

\subsection{Instrument}

The researchers developed the study's instrument based on several studies. Such studies include the ones conducted by Al-Soud (2015) and Al-Hajar (2017). The researchers developed the study's instrument to meet the study's goals and answer the study's questions. The initial version of the questionnaire consists from 30 items. The final version of the questionnaire consists from 27 items. It sheds a light on three areas. These areas are listed below:

1) Guidance: There are 8 items that are related to guidance

2) Coordination: There are 12 items that are related to coordination

3) Appreciation: There are 7 items that are related to coordination

\subsection{Validity}

To measure the content validity of the questionnaire, the researchers passed the initial version of the questionnaire to 9 experts. Those experts are specialized in the educational administration field. They were asked to assess the questionnaire in terms of relevancy, clarity and language. They were asked to make additions, deletions, or changes to the questionnaire. Based on the experts' opinions, changes were made to the questionnaire. Such changes include: adjustments, deletions, and merging items. The final version of the questionnaire consists from 27 items.

\subsection{Reliability}

To measure the reliability of the questionnaire, the Cronbach alpha coefficient values were calculated. Table 3 presents those values below.

Table 3. The Cronbach alpha coefficient values of the study's areas

\begin{tabular}{ccc}
\hline No. & Area & The Cronbach alpha coefficient value \\
\hline 1 & Guidance & 0.90 \\
2 & Coordination & 0.89 \\
3 & Appreciation & 0.87 \\
\hline
\end{tabular}

Based on Table 3, it was found that the Cronbach alpha coefficient values are accepted. Thus, the questionnaire offers results that are very reliable.

\subsection{Criteria for Classifying Means}

To classify means, the following criteria were adopted:

\subsection{3 or less: Low}

\subsection{4-3.67: Moderate}

3.68 or more: High

\section{Results and Discussion}

\subsection{Results and Discussion Related to the First Question}

Question one: What is the extent of practicing management by love in the inclusive schools in Qatar in terms of coordination, guidance, and appreciation from the perspective of administrators? 
To answer the first question, means and standard deviations are calculated for each area. Table 4 presents those values.

Table 4. The means and standard deviations for the extent of practicing management by love in the inclusive schools in Qatar in terms of coordination, guidance, and appreciation from the perspective of administrators

\begin{tabular}{cccccc}
\hline No. & Area & Mean. & Std. & Rank & Level \\
\hline 1 & Guidance & 3.68 & 0.90 & 1 & High \\
2 & Coordination & 3.57 & 0.89 & 2 & Moderate \\
3 & Appreciation & 3.32 & 1.03 & 3 & Moderate \\
& Overall & 3.54 & 0.92 & \multicolumn{2}{c}{ Moderate } \\
\hline
\end{tabular}

Based on Table 4, the extent of practicing management by love in the inclusive schools in Qatar is moderate. That's because the overall mean is 3.54 . The overall standard deviation is 0.92 . The mean of the guidance area is 3.68 which is high and ranked first. The standard deviation of the latter area is 0.90 . The mean of the coordination area is 3.57 which is moderate and ranked second. The standard deviation of the latter area is 0.89 . The mean of the appreciation area is 3.32 which is moderate and ranked third. The standard deviation of the latter area is 1.03 . The detailed results of each area are presented below separately.

1) The guidance area:

Means and standard deviations are calculated for this area. These values are shown through Table 5 below.

Table 5. The means and standard deviations of the guidance area:

\begin{tabular}{|c|c|c|c|c|c|}
\hline No. & Statement & Mean & Std. & Level & Attitude \\
\hline 2 & The school administration shares some (powers) with administrators when making decisions & 3.86 & 0.82 & 1 & High \\
\hline 8 & In external meetings, the school administration acts as a representative for administrators & 3.84 & 1.01 & 2 & High \\
\hline 7 & The school administration avoids being authoritative when dealing with administrators & 3.81 & 0.86 & 3 & High \\
\hline 1 & The school administration doesn't take action without consulting any one of the administrators & 3.77 & 0.92 & 4 & High \\
\hline 5 & $\begin{array}{l}\text { The school administration takes into consideration the potentials and capabilities of the } \\
\text { administrators when assigning academic duties to them }\end{array}$ & 3.72 & 1.00 & 5 & High \\
\hline 3 & $\begin{array}{l}\text { The school administration believes that holding discussions with administrators about } \\
\text { administrative issues is a waste of time }\end{array}$ & 2.89 & 1.03 & 12 & Moderate \\
\hline 4 & The school administration seeks complying with all the regulations & 2.74 & 1.06 & 13 & Moderate \\
\hline \multirow[t]{2}{*}{6} & $\begin{array}{l}\text { The school administration doesn't encourage teachers to communicate frequently with } \\
\text { administrators }\end{array}$ & 2.65 & 1.01 & 14 & Moderate \\
\hline & Overall & 3.68 & 0.90 & High & \\
\hline
\end{tabular}

Based on Table 5, the extent of practicing management by love in the inclusive schools in Qatar in terms of guidance is high from the perspective of administrators. That is because the overall mean is 3.68 . The overall standard deviation is 0.90 . The means in Table 5 are within the range of (3.86-3.65). The mean of statement (2) is ranked first. The latter statement states the following: "The school administration shares some (powers) with administrators when making decisions". The mean of statement (6) is ranked last. The latter statement states the following: "The school administration doesn't encourage teachers to communicate frequently with administrators".

The result in this regard may be attributed to having much expertise by administrators. Thus, administrators are highly capable of making achievements and handling responsibilities. Having this capability positively affects the way in which the administration guides administrators. It makes the administration dependent on administrators, It increase the extent of engaging administrators in doing administrative tasks at school. It promotes trust, affection, cooperation and mutual trust between the administration and the administrators. It contributes to offering support programs by the administration to administrators. However, management by love involves making decisions that are consistent with logic, rules, policies, and code of ethics. It involves offering guidance that develops employees, and raises their performance and enhance their behaviors. It involves offering guidance that promotes interaction among employees. It makes others willing to do duties and exert effort willingly. The latter result is consistent with the result concluded by Al-Soud (2018). 
2) The coordination area:

Means and standard deviations are calculated for this area. These values are shown through Table 6 below.

Table 6. The means and standard deviations of the coordination area

\begin{tabular}{|c|c|c|c|c|c|}
\hline No. & Statement & Mean & Std. & Level & Attitude \\
\hline 3 & Coordination enables the school to meet its goals & 3.63 & 1.10 & 1 & Moderate \\
\hline 5 & The coordination between the school administration and the administrators is carried out fast & 3.60 & 1.06 & 2 & Moderate \\
\hline 2 & The coordination at the school is characterized with flexibility & 3.60 & 1.06 & 2 & Moderate \\
\hline 4 & $\begin{array}{l}\text { There are several communication channels for having coordination with administrators of all } \\
\text { levels }\end{array}$ & 3.57 & 1.10 & 4 & Moderate \\
\hline 1 & $\begin{array}{l}\text { The school administration exerts much effort to overcome the barriers hindering the coordination } \\
\text { between the administrators }\end{array}$ & 3.54 & 1.05 & 5 & Moderate \\
\hline 6 & Through coordination in the school, accurate information shall be exchanged & 3.52 & 1.09 & 6 & Moderate \\
\hline 8 & $\begin{array}{l}\text { Coordination between the administration and the administrators of the top administrative level } \\
\text { can be made without barriers }\end{array}$ & 3.51 & 1.09 & 7 & Moderate \\
\hline 9 & $\begin{array}{l}\text { Through having coordination at the school, the information needed for making decisions shall be } \\
\text { provided }\end{array}$ & 3.49 & 1.04 & 8 & Moderate \\
\hline 12 & The coordination at the school is consistent with the job requirements & 3.47 & 0.89 & 9 & Moderate \\
\hline 10 & The coordination at the school enables the staff to carry out their duties fast & 3.41 & 1.01 & 10 & Moderate \\
\hline 7 & The coordination at the school raises the quality of the services provided to administrators & 3.40 & 0.91 & 11 & Moderate \\
\hline \multirow[t]{2}{*}{11} & $\begin{array}{l}\text { The school is keen on dealing positively with the administrative changes in order to improve } \\
\text { performance }\end{array}$ & 3.38 & 0.87 & 12 & Moderate \\
\hline & Total & 3.57 & 0.89 & & Moderate \\
\hline
\end{tabular}

Based on Table 6, the extent of practicing management by love in the inclusive schools in Qatar in terms of coordination is moderate from the perspective of administrators. That is because the overall mean is 3.57 . The overall standard deviation is 0.89 . The mean of statement (3) is ranked first. The latter statement states the following: "Coordination enables the school to meet its goals". The mean of statement (11) is ranked last. The latter statement states the following: "The school is keen on dealing positively with the administrative changes in order to improve performance".

The results in this regard may be attributed to the poor capability of the school administration in promoting harmony between all the administrators. Such poor capability may be attributed to having an organizational culture that is based on selfishness and vanity rather than love. It may be attributed to having an organizational culture that is based on having rigid policies. It may be attributed to the inadequacy of the attention given to employees. It may be attributed to the poor capability of the school administrators to interact effectively with the administration. That shall negatively affect the capability of the school administration to have efforts coordinated for meeting the intended goals.

The result in this regard may be attributed to having poor relationships between the administration and the administrators. Such poor relationships shall lead to wasting much effort exerted by the administration and the administrators. The result in this regard may be attributed to the inadequacy of the attention provided for the employees by the administration in social areas. It may be attributed to the inadequacy of the attention provided by the administration for organizational events. That shall negatively affect the extent of harmony and interaction between the administration and the employees. The latter result is consistent with the result concluded by Dobbins (2012).

3) The appreciation area

Means and standard deviations are calculated for this area. These values are shown through Table 7 below. 
Table 7. The means and standard deviations of the appreciation area

\begin{tabular}{|c|c|c|c|c|c|}
\hline No. & Statement & Mean & Std. & Level & Attitude \\
\hline 1 & Moral appreciation improves my performance & 3.58 & 1.21 & 1 & Moderate \\
\hline 3 & Financial appreciation improves my performance & 3.52 & 1.15 & 2 & Moderate \\
\hline 2 & The school I work at has a secure positive work climate & 3.45 & 1.35 & 3 & Moderate \\
\hline 7 & The school I work at shows appreciation to the ones who make distinguished achievements & 3.37 & 1.01 & 4 & Moderate \\
\hline 5 & $\begin{array}{l}\text { When the school administration gives promotions to the employees, it takes into } \\
\text { consideration the responsibilities assigned to each employee }\end{array}$ & 3.29 & 1.07 & 5 & Moderate \\
\hline 4 & $\begin{array}{l}\text { The school administration encourages administrators to develop new regulations for } \\
\text { showing appreciation to the staff }\end{array}$ & 3.21 & 1.29 & 6 & Moderate \\
\hline \multirow[t]{2}{*}{6} & $\begin{array}{l}\text { The appreciation shown by the school administration increases the loyalty of the } \\
\text { administrators to the school }\end{array}$ & 3.19 & 1.26 & 7 & Moderate \\
\hline & Total & 3.32 & 1.03 & Moderate & \\
\hline
\end{tabular}

Based on Table 7, the extent of practicing management by love in the inclusive schools in Qatar in terms of appreciation is moderate from the perspective of administrators. That is because the overall mean is 3.32 . The overall standard deviation is 1.03 . The means are within the range of (3.58-3.19). The mean of statement (1) is ranked first. The latter statement states the following: "Moral appreciation improves my performance". The mean of statement (6) is ranked first. The latter statement states the following: "The appreciation shown by the school administration increases the loyalty of the administrators to the school".

The result in this regard may be attributed to the poor capability of the school administration and employees to express their appreciation for the administrators who perform their duties well. It may be attributed to the poor faith that the administration has in the capabilities of the school staff. It may be attributed to the administration's interest in achieving a kind of consistency between the organizational values and the employees' values. The result in this regard may be attributed to the belief of the administration that the current incentive systems are effective and capable of meeting the employees' needs. The latter belief is inconsistent with the principles of the management by love. In fact, management by love aims at showing appreciation to others and their efforts in order to promote compliance with the organizational values.

The result in this regard may be attributed to the low loyalty level of administrators. It may be attributed to the unwillingness of the school administration to make changes and reforms in various departments and units. Such unwillingness shall negatively affect the extent of administrators' appreciation for the administration. It shall negatively affect the extent of administrators' trust in the administration. It shall negatively affect the extent of administrators' trust in the decisions made by the administration. It shall promote psychological alienation among administrators. It shall discourage administrators from doing their duties effectively. The result in this regard is consistent with the results concluded by Satu (2013) and Mohammad (2020).

\subsection{Results and Discussion Related To the Second Question}

Question two: Is there any statistically significant difference-at the statistical significance level of (a $\leq$ 0.05)-between the respondents' attitudes which can be attributed to (gender, experience or academic qualification)?

The detailed answers to this question are displayed below:

a) Results related to gender

To explore the results in this regard, means and standard deviations are calculated. In addition, the t-test was conducted. Table 8 shows these values. 
Table 8. Means and standard deviations and the t-test result for identifying the differences between the respondents' attitudes that are attributed to gender

\begin{tabular}{|c|c|c|c|c|c|c|}
\hline Area & Gender & Frequency & Mean & Std. & $\mathrm{T}$ value & Sig \\
\hline \multirow{3}{*}{ Guidance } & Female & 129 & 3.79 & 0.74 & \multirow{3}{*}{2.441} & \multirow{3}{*}{$* * 0.004$} \\
\hline & Male & 213 & 3.64 & 0.82 & & \\
\hline & Total & 342 & 3.74 & 0.79 & & \\
\hline \multirow{3}{*}{ Coordination } & Female & 129 & 3.57 & 0.88 & \multirow{3}{*}{0.862} & \multirow{3}{*}{0.372} \\
\hline & Male & 213 & 3.49 & 0.90 & & \\
\hline & Total & 342 & 3.52 & 0.89 & & \\
\hline \multirow{3}{*}{ Appreciation } & Female & 129 & 3.38 & 1.04 & \multirow{3}{*}{1.141} & \multirow{3}{*}{$* * 0.030$} \\
\hline & Male & 213 & 3.14 & 0.96 & & \\
\hline & Total & 342 & 3.37 & 1.01 & & \\
\hline \multirow{3}{*}{ Overall } & Female & 129 & 3.62 & 0.80 & \multirow{3}{*}{1.639} & \multirow{3}{*}{$0.009 * *$} \\
\hline & Male & 213 & 3.39 & 0.81 & & \\
\hline & Total & 342 & 3.51 & 1.67 & & \\
\hline
\end{tabular}

**: This sign means that the value is statistically significant at the statistical significance level of $(\mathrm{a} \leq 0.05)$.

To identify whether the differences between the means are statistically significant at the statistical significance level of $(a \leq 0.05)$, the t-test was conducted. Based on table (8), there is a statistically significant difference-at the statistical significance level of $(a \leq 0.05)$-between the respondents' attitudes which can be attributed to gender. That is because the calculated $t$ value is 1.639 and the significance value is 0.009 . The latter difference is for the favor of the males.

The latter result may be attributed to the capability of males to run schools effectively and offer attention to adolescents. It indicates that men are more capable than women to provide guidance, make orders and enable the employees to organize the duties assigned to them. It indicates that men are more capable than women to meet all the requirements needed for developing teachers. It indicates that men are more capable to run schools and interact effectively with the employees. It indicates that men are more capable to identify the needs of the employees and empathize with them.

The latter result indicates that men are more capable than women to unleash the employees' potentials and enable employees to enjoy a stable family life. It indicates that men are more capable than women to listen well to employees. It indicates that the need for appreciation is higher among men. Showing appreciation shall increase one's self-esteem, and make him/her value his/her duties. It shall make one believe in the organizational mission. It shall make one realize the significance of improving performance.

It was found that there isn't any statistically significant difference in the coordination area. That may be attributed to having much harmony and interaction between administrators. It may be attributed to the capability of males and females to make changes. Changes are made to increase the extent of engaging employees in the planning, organization and monitoring processes. However, making changes requires coordination and improving performance. The result in this regard may be attributed to the poor capabilities of males to express all their views and feelings clearly. That shall negatively affect their practices, performance, and way of doing tasks. The latter result is inconsistent with the result concluded by Ricky (2017)

b) Results related to experience

To explore the results in this regard, means and standard deviations are calculated for identifying whether there is any significant difference between the respondents' attitudes that can be attributed to experience. In addition, the t-test was conducted. Table 9 shows these values. 
Table 9. Means, standard deviations and the t-test results for identifying whether there is any significant difference between the respondents' attitudes that can be attributed to experience

\begin{tabular}{ccccccc}
\hline Area & Gender & Frequency & Mean & Std. & T value & Sig. \\
\hline \multirow{4}{*}{ Guidance } & Five years or less & 204 & 3.69 & 0.74 & & 0.074 \\
& More than five years & 138 & 3.82 & 0.83 & -673 & \\
& Total & 342 & 3.78 & 0.80 & & \\
Coordination & Five years or less & 204 & 3.41 & 0.93 & -3.428 & $* * 0.013$ \\
& More than five years & 138 & 3.64 & 0.89 & & \\
& Total & 342 & 3.56 & 0.92 & & \\
Appreciation & Five years or less & 204 & 3.25 & 1.05 & & \multirow{2}{*}{0.069} \\
& More than five years & 138 & 3.21 & 0.97 & & \\
& Total & 342 & 3.22 & 1.00 & & \\
Overall & Five years or less & 129 & 3.62 & 0.80 & & \multirow{2}{*}{0.202} \\
& More than five years & 213 & 3.39 & 0.81 & & \\
\hline
\end{tabular}

**: This sign means that the value is statistically significant at the statistical significance level of $(a \leq 0.05)$.

To identify whether the differences between the means are statistically significant at the statistical significance level of $(\mathrm{a} \leq 0.05)$, the t-test was conducted. Based on table (9), there isn't any statistically significant difference -at the statistical significance level of (a $\leq 0.05$ )-between the respondents' attitudes which can be attributed to experience. That is because the calculated $t$ value is -1.272 and the significance value is 0.202 . However, there is a difference in the coordination area for the favor of the ones who have more than five years of experience. The latter result may be attributed to adopting a management approach that is based on democracy and consultancy.

The results indicate that the ones who have more than five years of experience shall be more engaged in developing guidelines and making orders. In other words, the ones who have more than five years of exercise administrative powers more than others. The latter result may be attributed to having much interaction among the administrators who have more than five years of experience. There is much interaction among those administrators because the nature of their work requires having coordination and cooperation between them. The nature of their work also requires having coordination and cooperation between them from one hand and the school administration from another hand. Such coordination and cooperation shall make the school administration informed about the obstacles hindering those administrators from working well. Thus, the school administration shall provide more attention to developing, and rewarding those administrators and improving their living conditions.

The latter difference in the coordination area indicates that the administrators who possess five years or more realize that the goals and the mission of educational institutions are noble. Such realization shall make those administrators sacrificing and willing to acknowledge their mistakes and weaknesses. That shall encourage those administrators to develop themselves. It shall contribute to improving the institution. It shall allow the formation of administrative teams. It shall promote solidarity in the education institution without waiting for something in return. It shall make the administrators giving in an unlimited manner due to their love for the institution. The result in this regard is consistent with the results concluded by Mehta (2018) and Ricky (2017).

c) Results related to academic qualification

Means and standard deviations are calculated to identify the respondents' attitudes in accordance with their academic qualifications. Table 10 shows these values. 
Table 10. Means and standard deviations to identify the respondents' attitudes in accordance with their academic qualification

\begin{tabular}{ccccc}
\hline Variable & Category & Frequency & Mean & Std. \\
\hline \multirow{4}{*}{ Guidance } & Postgraduate degree & 64 & 3.79 & 0.55 \\
& BA degree & 98 & 3.88 & 0.82 \\
& Diploma & 109 & 3.76 & 0.79 \\
& Secondary school certificate & 71 & 3.65 & 0.73 \\
& Total & 342 & 3.76 & 0.76 \\
\hline \multirow{4}{*}{ Coordination } & Postgraduate degree & 64 & 3.54 & 0.85 \\
& BA degree & 98 & 3.68 & 0.86 \\
& Diploma & 109 & 3.59 & 0.90 \\
& Secondary school certificate & 71 & 3.54 & 0.89 \\
& Total & 342 & 3.73 & 0.87 \\
\hline \multirow{4}{*}{ Appreciation } & Postgraduate degree & 64 & 3.31 & 1.10 \\
& BA degree & 98 & 3.46 & 1.00 \\
& Diploma & 109 & 3.22 & 0.89 \\
& Secondary school certificate & 71 & 3.15 & 1.01 \\
& Total & 342 & 3.32 & 1.02 \\
\hline \multirow{6}{*}{ Overall } & Postgraduate degree & 64 & 3.58 & 1.61 \\
& BA degree & 98 & 3.67 & 1.70 \\
& Diploma & 109 & 3.52 & 1.62 \\
& Secondary school certificate & 71 & 3.41 & 0.86 \\
& Total & 342 & 3.58 & 1.48 \\
\hline
\end{tabular}

Based on Table 10, it appears that there are differences between the means which can be attributed to academic qualification. The latter differences are for the favor of the ones who hold BA degree. That's because the mean of the ones who have BA degree is 3.67 which is ranked first. The mean of the ones who hold postgraduate degree is 3.58 which is ranked second. The mean of the ones who hold secondary school certificate is 3.41 which is ranked last. The latter result may be attributed to the fact that the ones who hold BA degree are in need for attention and appreciation more than others. It may be attributed to the fact that the ones who hold BA degree are in need for having their tasks coordinated more than others. Such coordination shall positively affect the psychological and emotional security of those administrators. To identify whether these differences are statistically significant or not at the statistical significance level of $(a \leq 0.05)$-one way analysis of variance (ANOVA) was conducted. The results of the latter analysis are presented in Table 11 below.

Table 11. The results of the one way analysis of variance (ANOVA) to the identify whether the differences attributed to academic qualification are statistically significant or not

\begin{tabular}{ccccccc}
\hline & Source of variance & Sum of squares & Df. & Mean square & F value & Sig. \\
\hline \multirow{4}{*}{ Guidance } & Between groups & 1.761 & 3 & 0.681 & & \\
& Within groups & 203.447 & 349 & 0.552 & 1.015 & 0.289 \\
& Total & 313.241 & 352 & & & \\
& Between groups & 1.784 & 3 & 0.765 & & \\
Coordination & Within groups & 290.198 & 349 & 0.831 & 0.504 & 0.332 \\
& Total & 292.493 & 352 & & & \\
& Between groups & 4.069 & 3 & 1.290 & & \\
& Within groups & 321.207 & 349 & 0.688 & 1.446 & 0.286 \\
& Total & 327.275 & 352 & & & \\
& Between groups & 3.076 & 3 & 0.376 & & \\
& Within groups & 384.157 & 349 & 0.341 & 0.823 & 0.58 \\
& Total & & 352 & & & \\
\hline \multirow{5}{*}{ Overall } & & & & & &
\end{tabular}

Based on Table 11, it was found that there isn't any statistically significant difference -at the statistical significance level of $(\mathrm{a} \leq 0.05)$-between the respondents' attitudes which can be attributed to academic qualification. That is 
because the calculated $\mathrm{F}$ value is 0.823 and the significance value is 0.58 . The latter result indicates that administrators of all academic qualifications show appreciation, and willingness to interact and collaborate with others. That shall enable administrators to achieve their ambitions and develop their capabilities and potentials. It shall lead to promoting harmony among administrators. It shall integrate administrators in the organizational environment. It shall enable administrators to meet their professional expectations and ambitions.

The latter result may be attributed to the nature of the organizational climate. For instance, the administrations in the targeted schools provide much attention to rewards and incentives. The latter result may be attributed to the fact that administrations in the targeted schools provide much attention to cultural aspects and human behaviors. It may be attributed to the fact that administrations in the targeted schools seek promoting positive behaviors among administrators.

In the guidance area, when comparing the administrators holding BA degree with the administrators holding secondary school certificate, the differences are for the favor of the administrators holding BA degree. In the coordination area, when comparing the administrators holding BA degree with the administrators holding diploma degree, the differences are for the favor of the administrators holding BA degree. In the appreciation area, when comparing the administrators holding BA degree with the administrators holding secondary school certificate, the difference is for the favor of the administrators holding BA degree. Scheffe test was conducted for identifying the ones whose the academic qualification-related differences are for their favor in the areas. Table 12 presents the results of the latter test.

Table 12. The results of Scheffe Test for identifying the ones whose the academic qualification-related differences are for their favor

\begin{tabular}{cccccc}
\hline \multirow{2}{*}{ Academic qualification } & \multirow{2}{*}{ Mean } & Postgraduate degree & BA degree & Diploma degree & Secondary school certificate \\
\cline { 3 - 6 } & & 3.59 & 3.68 & 3.52 & 3.43 \\
\hline Postgraduate degree & 3.59 & - & 0.952 & 0.934 & 0.712 \\
BA degree & 3.68 & 0.952 & - & 0.387 & $0.243^{*}$ \\
Diploma & 3.52 & 0.934 & 0.387 & - & 0.732 \\
Secondary school certificate & 3.43 & 0.712 & 0.243 & 0.732 & - \\
\hline
\end{tabular}

*: This sign means that the value is statistically significant at the statistical significance level of $(a \leq 0.05)$.

Based on Table 12, when comparing the administrators holding BA degree with the administrators holding secondary school certificate, the difference is for the favor of the administrators holding BA degree

\section{Conclusion}

It was found that the extent of practicing management by love in the inclusive schools in Qatar is moderate from the perspective of administrators. It was found that there is a statistically significant difference -at the statistical significance level of $(a \leq 0.05)$-between the respondents' attitudes which can be attributed to gender. The latter differences are for the favor of males. It was found that there isn't any statistically significant difference -at the statistical significance level of $(\mathrm{a} \leq 0.05)$-between the respondents' attitudes which can be attributed to experience, or academic qualification

\section{Recommendations}

In the light of the aforementioned results, the researchers recommend:

Providing management by love with more attention by the Ministry of Higher Education and Scientific Research in Qatar. The latter ministry should conduct studies regularly to explore the living conditions of employees working in higher education institutions. They should conduct studies regularly to explore the economic, social and psychological problems of the employees working in higher education institutions.

Improving the systems used for appreciating employees for their efforts and the systems used for rewarding the ones who make distinguished achievements.

Increasing the degree to which employees are engaged in doing tasks. The researchers recommend developing employees professionally

Holding training courses and symposiums for administrators at schools in order to promote knowledge among them about management by love. The researchers recommend promoting interaction between the administration and employees in schools. 
Conducting more studies that aim at shedding a light on management by love and its impact on the performance of educational institutions. The researchers recommend conducting more studies about the outcomes of management by love.

\section{Acknowledgments}

The researchers would like to thank Qatar University for its support.

\section{References}

Abu Al-Naser, M. (2005). Natural language processing. Cairo. Egypt: Al-Neel Al-Arabeye.

Al-Bahar, I. (2018). Proposed administrative measures for establishing a healthy organizational climate in Private Jordanian universities based on Likert scale (Unpublished $\mathrm{PhD}$ dissertation). The University of Jordan, Amman, Jordan.

Al-Hajar, R. (2017). The extent of practicing authentic leadership by secondary school principals in Gaza and its relationship with some variables. The Journal of Al-Aqsa University, 21(2), 207-234. https://doi.org/10.12816/0044919

Al-Soud, R. (2015). Contemporary trends in educational administration: Management by love (motherhood-based management). The First International Conference: Education and Future Prospects, Al-Baha University, Kingdom of Saudi Arabia, 1(1), 261-272.

Al-Soud, R. (2015). Educational leadership: Concepts and prospects. Amman, Jordan: Dar Safa'.

Al-Taweel, H. (2010). Organizational behavior in educational organizations. Amman. Jordan: Dar Wa'el.

Al-Wabili, A. (2018). Essential concepts in special education. Riyad, Saudi Arabia: Dar Al-Ma'refeh.

Al-Zoubi, A. (2001). Foundations of socio-psychology. Amman. Jordan: Dar Zahran.

Dobbins, T. (2012). What 21st Century Leadership in Career and Technical education should look like (Unpublished MA thesis). The Middle Bucks Institute of Technology, New York, United States.

Hamshari, O. (2013). Knowledge management. Amman, Jordan.

Harris, J. (1996). Getting Employees to Fall in Love with Your Company (1st ed.). New York. United States: Amacom

Khandelwal, N. (2018). Leadership by 'Love': A Divine Paradig. Journal of Symbiosis Centre for Management Studies, 6(1), 38-56.

Lee, J. A. (1973). Colors of love: an exploration of the ways of loving. Toronto, Canada: New Press.

Määttä, K. (2014). The psychology of study success in universities. International Journal of Education, 6(3), 180-198.

Mehta, A. (2018). Leadership by 'Love': A Divine Paradig. Journal of Symbiosis Centre for Management Studies, $6(1), 38-56$.

Mohammad, I. (2020). The Extent of Having Interactive Justice in Jordanian Private Universities in the Fields of Communication and Leadership. Journal of Education and Practice, 11(8), 142-150.

Ricky. (2017). Servant leadership in higher education: A case of academic leadership in a faith-based university in Indonesia (Unpublished MA thesis). The University of Birmingham, Britain.

Rubin, Z. (1970). Measurement of romantic love. Journal of Personality and Social Psychology, 2(14), 107-129. https://doi.org/10.1037/h0029841

Sanford, K. (1998). Leading with love: How women and men can transform their organizations through materialistic management. Washington, United States: Vashon publishing.

Satu, U. (2013). Love-Based leadership in early childhood education. Journal of Education Culture and Society, 1(2), 109-120.

Sternberg, R. (2007). Triangulating love. Ohio: The Altruism Reader.

Viviano, T. (2012). What 21st Century Leadership in Career and Technical Education Should Look Like (Unpublished MA thesis). Middle Bucks Institute of Technology, New York. https://doi.org/10.21061/jcte.v27i2.559 


\section{Copyrights}

Copyright for this article is retained by the author(s), with first publication rights granted to the journal.

This is an open-access article distributed under the terms and conditions of the Creative Commons Attribution license (http://creativecommons.org/licenses/by/4.0/). 